\title{
MIXED MATING IN HOMOSTYLOUS SPECIES: GENETIC AND EXPERIMENTAL EVIDENCE FROM AN ALPINE PLANT WITH VARIABLE HERKOGAMY, PRIMULA HALLERI
}

\author{
Jurriaan M. de Vos, ${ }^{1,2, *}$ Barbara Keller, ${ }^{1}+$ Li-Rui Zhang,, Michael D. Nowak, $\neq$ and Elena Conti† \\ *Department of Comparative Plant and Fungal Biology, Royal Botanic Gardens, Kew, Richmond, Surrey TW9 3DS, United Kingdom; \\ tDepartment of Systematic and Evolutionary Botany, University of Zürich, Zollikerstrasse 107, 8008 Zürich, Switzerland; \\ and $¥$ Natural History Museum, University of Oslo, Sars’ gate 1, 0562 Oslo, Norway
}

Editor: Christina Caruso

\begin{abstract}
Premise of research. Self-compatibility is a requirement for reproductive assurance via selfing and may therefore be beneficial in environments with infrequent or unpredictable pollinator service. However, selfcompatible plants may spatially separate anthers from stigmatic surface within flowers (herkogamy), potentially preventing autonomous self-pollination while promoting outcrossing. We investigated the effects of herkogamy on patterns of mating in a self-compatible, homostylous alpine herb, Primula halleri, which evolved from obligately outcrossing, heterostylous ancestors. Primula halleri displays diminishing herkogamy during anthesis, affecting its capacity for self-pollination. Specifically, we tested whether higher herkogamy at the end of anthesis (terminal herkogamy) promotes higher outcrossing rates at the cost of lower seed set, while lower terminal herkogamy ensures seed set via self-pollination at the cost of inbreeding.

Methodology. We estimated family- and population-level genetic outcrossing rates in four populations using microsatellites and derived an estimate for inbreeding depression. We tested effects of different levels of terminal herkogamy on means and variances of outcrossing rates. We also assessed whether seed set was resource or pollen limited. We interpreted results in light of previously published data on seed set with and without pollinator-exclusion treatment.
\end{abstract}

Pivotal results. Population-level outcrossing rates ranged between 0.5 and 0.8 . Outcrossing rates of plants with higher terminal herkogamy had similar means but lower variances than those of plants with lower terminal herkogamy. This result demonstrates that separation between sexual organs larger than $1 \mathrm{~mm}$ in mature flowers favors outbreeding, while below this threshold, delayed selfing ensures reproduction.

Conclusions. Contrary to long-held notions about the association of homostyly and selfing, we provide new genetic evidence that the homostylous $P$. halleri adopts a mixed mating system due to variable herkogamy. Moreover, our results support a trade-off between seed number and seed quality effected through variation in herkogamy, illustrating that herkogamy affects multiple aspects of reproductive fitness simultaneously.

Keywords: Primula, homostyly, herkogamy, flowers, reproduction, alpine plants.

Online enhancements: appendix tables.

\section{Introduction}

Plant sexual reproduction requires receipt of pollen grains onto a carpel. Outcrossing plants rely on the provisioning of pollen grains through the service of pollen vectors; thus, their mating success depends on the abundance and efficiency of pollen vectors (Aizen and Harder 2007). It is now widely accepted that plant reproduction is frequently pollen limited (e.g., Larson

\footnotetext{
1 These authors contributed equally to the study.

2 Author for correspondence; current address: Department of Environmental Sciences-Botany, University of Basel, Basel, Switzerland; e-mail: jurriaan.devos@unibas.ch.
}

Manuscript received July 2017; revised manuscript received October 2017; electronically published January 16, 2018. and Barrett 2000; Ashman et al. 2004; Knight et al. 2005). In biotically pollinated plants, this is typically due to the infrequent or unreliable availability of pollinator service (but see Aizen and Harder 2007). To overcome the challenges associated with limited pollinator service, different adaptive solutions may evolve (Harder and Aizen 2010). Two commonly observed strategies are increasing pollination probability and reducing reliance on pollinators (Arroyo et al. 2006). The probability of pollination can be heightened through higher floral attractiveness, achieved via more conspicuous floral displays (Müller 1881; Arroyo et al. 2006) or greater floral longevity (Bingham and Orthner 1998). Alternatively, pollinator reliance can be reduced by promoting reproductive assurance via autonomous self-pollination (Kalisz and Vogler 2003; Arroyo et al. 2006; Eckert et al. 2006). Decreased reliance on pollinators requires self-compatibility. 
Self-compatible plants lack the self-incompatibility mechanisms that prevent the delivery of male gametes to the egg after pollen has been transferred to the stigma (de Nettancourt 2001; Igić et al. 2008). Additionally, reduced reliance on pollinators requires a floral configuration that enables deposition of pollen on stigmas within flowers without the aid of pollinators. Thus, these two strategies fundamentally differ in the probability of producing outcrossed versus selfed progeny.

The relative frequency of seed set through selfing and outcrossing has important evolutionary consequences. It is referred to as the mating system and is quantified as the selfing rate, $s$, or its complement, the outcrossing rate, $t$ (where $t=1-s$; Lloyd and Schoen 1992; Barrett and Harder 1996; Barrett 2003). Although an intermediate amount of selfing is common among animal-pollinated, hermaphroditic species (i.e., mixed mating: $0.2<s<0.8$; Lande and Schemske 1985; Goodwillie et al. 2005), the evolutionary dynamics of mixed mating systems remain elusive. Selfed progeny are frequently less fit than outcrossed progeny due to inbreeding depression, which is largely caused by the expression of deleterious recessive alleles in homozygotes that rise in frequency due to selfing (Charlesworth and Willis 2009). In addition, sustained high levels of selfing can also decrease genetic variation in populations (Hamrick and Godt 1996), which may affect macroevolutionary patterns of diversification (Stebbins 1974), for instance, through increased extinction risk (Goldberg et al. 2010; Igić and Busch 2013; de Vos et al. 2014a). Theoretical studies emphasized individual reproductive fitness components (i.e., number of selfed ovules, outcrossed ovules, and ovules fertilized through pollen export) and suggested that functional interactions or trade-offs between them predict many possibilities for intermediate selfing rates that are evolutionarily stable (Harder and Routley 2006; Johnston et al. 2009; Devaux et al. 2013). Thus, to explain the evolution of plant mating systems, it is crucial to understand how individual reproductive traits interact with multiple aspects of seed set through self- and crosspollination in specific pollination environments.

In this study, we investigate the reproductive consequences of variation in one important floral trait: the spatial separation between male and female reproductive organs (i.e., herkogamy; Webb and Lloyd 1986). Although the preponderance of studies indicates that greater separation between sexual organs favors outcrossing, the effects of herkogamy on plant reproduction may be complex and remain poorly documented, especially when herkogamy decreases through anthesis. In self-compatible species, herkogamy has been mainly proposed as a mechanism to limit selfing, but it also influences sexual interference between male and female floral functions (Barrett 2002). Herkogamy negatively affects seed set when pollinators are absent (e.g., Luijten et al. 1999; Moeller 2006; de Vos et al. 2012), and several genetic analyses confirmed the expected positive correlation between herkogamy and outcrossing rates, both among (e.g., Rick et al. 1977; Holtsford and Ellstrand 1992; Luo and Widmer 2013) and within populations (e.g., Karron et al. 1997; Brunet and Eckert 1998; Takebayashi et al. 2006; Herlihy and Eckert 2007; Weber et al. 2012; but see Medrano et al. 2005, 2012). Importantly, herkogamy is known to decrease during anthesis in some species, potentially increasing opportunity for autonomous selfing in later stages of anthesis (Luijten et al. 1999; Armbruster et al. 2002; Duan et al. 2010; de Vos et al. 2012). Such delayed selfing represents a mechanism whereby selfing can provide reproductive assurance without interfering with outcrossing opportunities in early anthesis (Lloyd 1992; Lloyd and Schoen 1992; Kalisz et al. 1999, 2004; Eckert et al. 2006) Thus, delayed selfing enables the benefits of selfing via increasing total reproductive output, without incurring the discounting costs associated with using gametes for selfing that could have been otherwise outcrossed (Herlihy and Eckert 2002). Delayed selfing was proposed to always be favored by selection (Lloyd 1992), offering an explanation for mixed mating as a best-ofboth-worlds solution to the problem of unreliable pollinator service (Kalisz et al. 2004; Morgan and Wilson 2005). However, the mating system consequences of decreasing herkogamy during anthesis may be complex, as they can lead to particularly variable selfing rates (Pérez et al. 2013), and they remain generally poorly documented.

Our specific focus is on a self-compatible species of alpine (i.e., above tree line) meadows, Primula halleri J.F.Gmel. (Primulaceae). The species is a classic example of the evolution of self-compatiblity in marginal environments in the form of homostyly, from a heterostylous, obligately outcrossing ancestor (Guggisberg et al. 2006, 2009; de Vos et al. 2014a). Distylous (i.e., dimorphic heterostylous) species are obligately outcrossing, with plants differing in the reciprocal positioning of anthers and stigmas in the two complementary floral morphs and characterized by a genetic incompatibility system that prevents pollen germination within the same individual or floral morph (reviewed, e.g., in Darwin 1877; Barrett 1992; Cohen 2010). In contrast, P. halleri is a homostylous, self-compatible species in which distyly is lost via mutations within the supergene that controls it (Huu et al. 2016; Li et al. 2016). It has long been held that the switch from heterostyly to homostyly is associated with the shift from outcrossing to selfing (Ernst 1955; Barrett 1992). Alpine environments, such as that of $P$. halleri, are thought to have generally depauperate pollinator faunas, with infrequent and unreliable pollination service compared with environments at the lower elevations, where the heterostylous relatives of $P$. halleri occur (Müller 1881; Arroyo et al. 1982, 1985, 2006; Bingham and Orthner 1998; Körner 2003). Thus, the evolution of homostyly in $P$. halleri is at first sight in line with the reduced pollinator reliance hypothesis.

Homostyly has been interpreted as an adaptation to promote autonomous selfing in marginal environments with low pollinator availability (e.g., in Primula [Guggisberg et al. 2006; Carlson et al. 2008] and Nymphoides [Haddadchi and Fatemi 2015]), but variation in herkogamy in homostylous species challenges this predominant view. Homostylous plants often present variation in the positions of anthers and stigmas within flowers (e.g., Barrett and Shore 1987; Johnston and Schoen 1996; Medrano et al. 2005; de Vos et al. 2014b; Sosenski et al. 2016), including $P$. halleri (de Vos et al. 2012; 2014b; note that we use homostyly and monomorphy in the context of heterostyly interchangeably, as both terms refer to presence of one, rather than multiple, style morphs, irrespective of stigma position relative to anthers). Specifically, field experiments documented that in P. halleri, herkogamy decreases throughout anthesis (on average, about $0.24 \mathrm{~mm}$ per day), but the terminal expression of herkogamy differs between individuals and populations (ranging ca. $0-4 \mathrm{~mm}$; de Vos et al. 2012; see also fig. 1). Importantly, autonomous selfpollination is only possible with less than $1 \mathrm{~mm}$ terminal herkogamy (de Vos et al.2012). Thus, herkogamy variation suggests that 

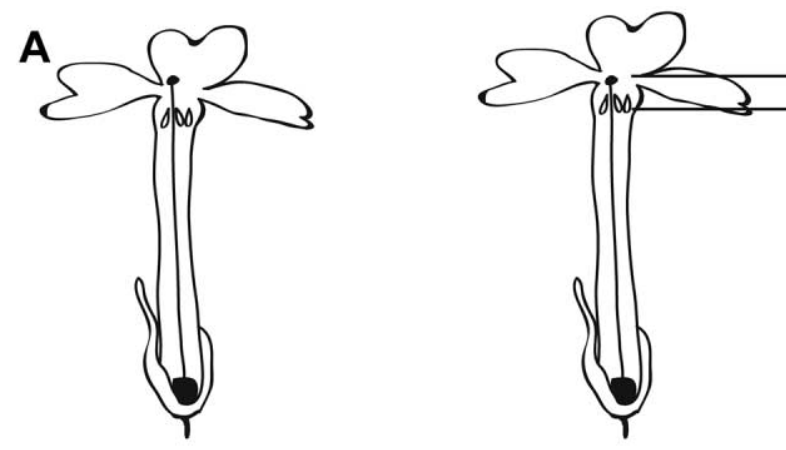

\author{
c $-\mathrm{b}$ \\ High terminal herkogamy: \\ With pollinator: \\ Outcrossing \& \\ facilitated selfing \\ Without pollinator: \\ Neither outcrossing \\ nor selfing
}

\title{
Early anthesis: :- Late anthesis: More herkogamy Less herkogamy
}
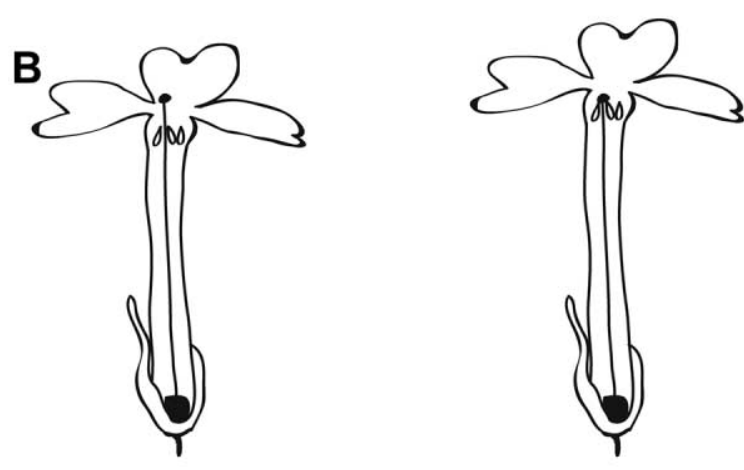

\section{Low terminal herkogamy: \\ With pollinator: \\ Outcrossing \& \\ facilitated selfing \\ Without pollinator: \\ Delayed autonomous selfing}

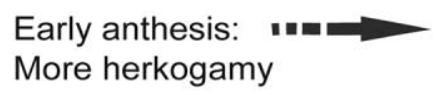

Late anthesis:

Less herkogamy

Fig. 1 Predicted modes of seed production in early (left side) versus late (right side) anthetic flowers of Primula halleri belonging to high and low terminal herkogamy classes $(A:>1 \mathrm{~mm}$, top panels; $B: 0-1 \mathrm{~mm}$, bottom panels), based on results of field experiments by de Vos et al (2012). Arrows indicate floral developmental time: both early and late anthetic flowers in $(A)$ and $(B)$ produce outcrossed and selfed seeds when pollinators are present; however, only late anthetic flowers in $(B)$ can produce seeds without pollinators, via autonomous selfing.

the reduced pollinator reliance hypothesis may not necessarily explain the occurrence of homostylous species in marginal environments.

We investigated the mating system consequences of herkogamy in the homostylous $P$. halleri by genotyping plants from natural populations and progeny arrays using recently developed microsatellite markers (Zhang et al. 2013). Specifically, we tested whether (i) natural populations exhibit mixed mating, (ii) the level of terminal herkogamy affects the mean and variance of the outcrossing rate, (iii) selfed progeny shows genetic evidence for potentially reduced fitness, and (iv) availability of pollen from other plants limits seed set. We expect that plants with an option for delayed autonomous selfing will have higher variances in outcrossing rates than plants that cannot autonomously self (i.e., obligately outcrossed plants; Perez et al. 2013). Therefore, we expect that plants with high terminal herkogamy will have a consistently high outcrossing rate, while plants with low terminal herkogamy will display a broader range of outcrossing rates, from fully outcrossing (if pollination was successful early in anthesis) to fully selfing (if no pollinator visited and delayed selfing occurred; fig. 1). Besides providing detailed evidence about the reproductive effects of specific floral trait var- iation in an alpine species, the results allow us to address the extent to which reproductive assurance and the reduced pollinator reliance hypothesis explain reproductive patterns in homostylous species.

\section{Material and Methods}

$$
\text { Study System }
$$

Primula halleri J.F.Gmel. is an iteroparous perennial rosette species that occurs scattered across the Alps, the Carpathians, and other mountain ranges in southeastern Europe, typically in nutrient-poor alpine meadows with southern exposure. Plants of $P$. halleri produce a single umbel of 3-19 (8.6 \pm 2.7 , mean \pm SD) hermaphroditic flowers, with each flower producing ca. 250330 ovules (de Vos et al. 2012). Field experiments demonstrated that anthesis lasts 6-12 d per flower, with overlapping male and female phases, and that pollination does not induce wilting (de Vos et al. 2012). One or two flowers open per day in a sequence from bottom (outside) to top (center) of the inflorescence; a single plant bears open flowers for up to $3 \mathrm{wk}$. The species appears to be exclusively pollinated by the hummingbird hawkmoth 
(Sphingidae: Macroglossum stellatarum Linnaeus, 1758), a migrating, day-active hawkmoth that visits very erratically. It is not observed on most days during the flowering season but appears to be effective when present (Schulz 1890; J. M. de Vos and B. Keller, personal observations).

The effects of terminal herkogamy on seed set per flower have been described (de Vos et al. 2012). In summary, mean seed set under open pollination decreases significantly from $0.78 \pm 0.03$ (mean \pm standard error of sample mean) seeds per ovule in plants with $<1 \mathrm{~mm}$ terminal herkogamy (i.e., lowherkogamous plants) to $0.64 \pm 0.04$ seeds per ovule in plants with $>1 \mathrm{~mm}$ terminal herkogamy (i.e., high-herkogamous plants; data from de Vos 2012). Herkogamy strongly affects seed set under pollinator exclusion, where seed set depends on autonomous selfing, with high-herkogamous plants producing very few seeds (mean $0.07 \pm 0.03$ seeds per ovule) and lowherkogamous plants producing significantly more seeds (mean $0.43 \pm 0.04$ seeds per ovule; full seed set with more than 0.9 seeds per ovule in $26 \%$ of flowers).

\section{Field Collections}

Four populations of $P$. halleri were sampled in the canton of Valais in Switzerland from June to September 2009. Estimates of population size ranged from several hundred individuals in populations $\mathrm{CH} 1$ and $\mathrm{CH} 3$ to several thousand individuals in populations $\mathrm{CH} 2$ and $\mathrm{CH} 4$. We assigned each flowering individual on a linear transect through each population to one of two herkogamy classes $(0-1 \mathrm{~mm}$ and $>1 \mathrm{~mm})$ based on the least herkogamous flower in the inflorescence. Assignment to herkogamy class was performed by visually scoring mature flowers, thus avoiding damage to flowers or their accidental pollination through manual handling (see also Medrano et al.2005) and was based on 25-131 plants per population. For genetic analyses (addressing questions i-iii), we randomly selected 24-32 plants from each population (not along the transect but throughout the population), for a total of 106 plants, determined their terminal herkogamy, and collected leaf tissue on silica gel. At the end of the blooming period, we bagged all flowers from the selected plants to prevent seed loss. Ripe capsules were collected at the end of the season for harvesting seeds to be used in progeny array studies. Capsules were scored for presence/absence of seeds and stored at $4^{\circ} \mathrm{C}$ for at least several months at the University of Zurich to break seed dormancy.

\section{Seed Germination for Progeny Arrays}

Fifty-eight out of the 106 plants produced capsules with seeds. For each of these, all available seeds from all capsules were pooled, and 200 randomly selected seeds per plant were sown in a single pot in the alpine greenhouse of the University of Zurich in January 2011. If a plant had less than 200 seeds, all seeds were sown. After germination, 24 seedlings per seed family were randomly selected for genotyping; all available seedlings were collected if a family had fewer than 24 seedlings. Overall, we sampled 5-24 seedlings for each of 7-20 plants per population, resulting in a total of 1240 seedlings representing 58 seed families, with a mean of 21.4 seedlings per family. The 1240 seedlings were harvested and stored at $-80^{\circ} \mathrm{C}$ prior to DNA extraction and genotyping.

\section{Microsatellite Amplification and Genotyping}

Using a modified CTAB protocol (Doyle and Doyle 1987; Cullings 1992), total genomic DNA was extracted from all 106 plants collected in the field and 1240 seedlings grown in the greenhouse. All plants were genotyped with 11 microsatellite markers specifically developed for $P$. halleri (Zhang et al. 2013). Although $P$. halleri has a tetraploid chromosome number $(2 n=4 x=56)$, these loci contain maximally two alleles per individual, suggesting that the genome of $P$. halleri is diploidized (Zhang et al. 2013). The loci were amplified in three multiplexed PCRs, each with three or four primer pairs combined, using three fluorescent dyes (FAM, PET, or NED) or a nonoverlapping distribution of expected amplicon size (table 1). PCR was performed in a total volume of $10 \mu \mathrm{L}$, containing $5 \mu \mathrm{L}$ Qiagen Multiplex PCR Master Mix, 0.6-1.0 $\mu \mathrm{L}$ of $10 \mu \mathrm{M}$ mixed primers based on each multiplex combination (table 1), $1 \mu \mathrm{L}$ Q-solution, $0.2 \mu \mathrm{L}$ template DNA, and RNAse-free water to the full volume. PCR amplifications were conducted with an initial denaturation step of $15 \mathrm{~min}$ at $95^{\circ} \mathrm{C}, 24$ cycles of $30 \mathrm{~s}$ at $95^{\circ} \mathrm{C}, 1 \mathrm{~min}$ at $55^{\circ} \mathrm{C}$, and $1 \mathrm{~min}$ at $72^{\circ} \mathrm{C}$, followed by a final elongation step of $10 \mathrm{~min}$ at $72^{\circ} \mathrm{C}$. Fragments were detected on an ABI Prism 3130 genetic analyzer (Applied Biosystems), and allele sizes were scored with GeneMapper software v4.1 (Applied Biosystems).

\section{Data Analyses}

Genetic variation. Genetic variation among and within populations was computed from the genotypes of all 106 plants collected in the field using FSTAT v. 2.9.3 (Goudet 1995). We estimated the mean number of alleles $\left(N_{\mathrm{a}}\right)$, allelic richness $(A$; El Mousadik and Petit 1996), and mean Nei's gene diversity $\left(H_{\mathrm{S}}\right.$; Nei 1987) for each population and locus. Genepop v. 4.2 (Rousset 2008) was used to test for departures from HardyWeinberg equilibrium using Fisher's exact test.

Outcrossing rates. The outcrossing rate of each population was estimated using a progeny array approach (see Ritland and Jain 1981; Shaw et al. 1981; reviewed by Jarne and David 2008; sample sizes per population in table A2; tables A1, A2 available online). To establish whether each population has a mixed mating system (question i), we estimated multilocus outcrossing rates $\left(t_{\mathrm{m}}\right)$, average single-locus outcrossing rates $\left(t_{\mathrm{s}}\right)$, and the level of biparental inbreeding $\left(t_{\mathrm{m}}-t_{\mathrm{s}}\right)$. To be able to test the effect of herkogamy on means and variances of the selfing rate (question ii), we estimated family-level, multilocus outcrossing rates $\left(t_{\mathrm{mf}}\right)$ for each maternal plant. All analyses of outcrossing rates were implemented in the software MLTR v. 3.4 (Ritland 2002); standard errors for all parameters were inferred from 1000 bootstrap replicates generated with the progeny array as the unit of resampling over families.

Herkogamy and family-level outcrossing rates. To address question ii, we tested two hypotheses regarding the effect of herkogamy on outcrossing rates. First, we tested whether highherkogamous plants had significantly higher mean outcrossing rates than low-herkogamous ones. This was accomplished by fitting a model with normal error distribution and identity link 
Table 1

Multiplexing Procedure for PCRs of 11 Microsatellite Primers in Primula halleri

\begin{tabular}{|c|c|c|c|c|c|}
\hline $\begin{array}{l}\text { Locus and } \\
\text { multiplex }\end{array}$ & Primer sequence $\left(5^{\prime}-3^{\prime}\right)$ & Repeat motif & Size range $(b p)^{a}$ & Dye $^{\mathrm{b}}$ & Primer concentration $(\mu \mathrm{M})^{\mathrm{c}}$ \\
\hline \multicolumn{6}{|l|}{ H15: } \\
\hline 1 & $\begin{array}{l}\text { F: CTTCCTTGCCGTCTGCTTG, } \\
\text { R: GATACCGATCCGCGTCCTC }\end{array}$ & $(\mathrm{AG})_{9}$ & $231-245$ & PET & .2 \\
\hline \multicolumn{6}{|c|}{ (1) } \\
\hline 1 & $\begin{array}{l}\text { F: GCCTTGGAAAGGAGAATGAGG, } \\
\text { R: GCCAAGGTTCTTGCGTACAG }\end{array}$ & $(\mathrm{AG})_{11}$ & $178-184$ & NED & .2 \\
\hline \multicolumn{6}{|l|}{ H22: } \\
\hline 1 & $\begin{array}{l}\text { F: TCCTGATGGATAAAACACGAGC, } \\
\text { R: GGCCTCACCACTGGATTTC }\end{array}$ & $(\mathrm{CT})_{10}$ & $160-170$ & NED & .2 \\
\hline \multicolumn{6}{|c|}{ 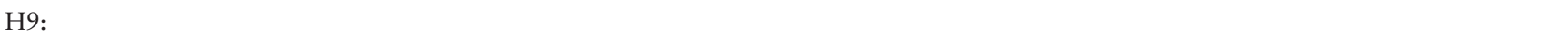 } \\
\hline 1 & $\begin{array}{l}\text { F: GAGTTCCTCCTCTAGCAGCC, } \\
\text { R: CCAACCCAAACCCCATCC }\end{array}$ & $(\mathrm{AAAG})_{7}$ & $190-210$ & YAM & .2 \\
\hline \multicolumn{6}{|c|}{ 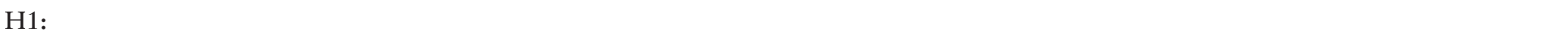 } \\
\hline 2 & $\begin{array}{l}\text { F: TCGTTCAGTACTCTATTCTCCC, } \\
\text { R: ACCACGTCAAAATCATAAAACCG }\end{array}$ & $(\mathrm{CT})_{10}(\mathrm{AT})_{7}$ & $250-260$ & PET & .3 \\
\hline \multicolumn{6}{|c|}{ 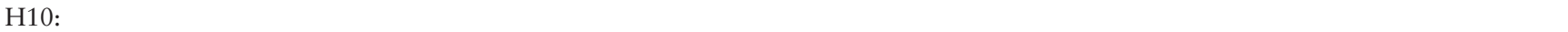 } \\
\hline 2 & $\begin{array}{l}\text { F: GGAATGCCTTTGACTAATGGG, } \\
\text { R: GTCTGGTATCTCATCATCTCGC }\end{array}$ & $(\mathrm{ATGT})_{6}$ & $150-158$ & YAM & .4 \\
\hline \multicolumn{6}{|c|}{ 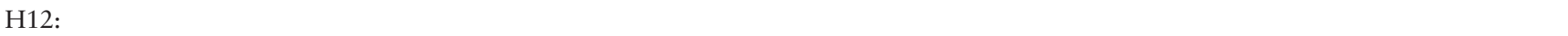 } \\
\hline 2 & $\begin{array}{l}\text { F: CGAACTTTCAGGTCACCCC, } \\
\text { R: ACTCCAGTTTGATGCCATTTCTC }\end{array}$ & $(\mathrm{ATGT})_{5}$ & $177-181$ & NED & .2 \\
\hline \multicolumn{6}{|c|}{ ( } \\
\hline 2 & $\begin{array}{l}\text { F: CCCGACACAAAGTTAAAACACG } \\
\text { R: CGTAGATTGAAATGAACGTAAACAG }\end{array}$ & $(\mathrm{CT})_{13}$ & 184-198 & PET & .2 \\
\hline \multicolumn{6}{|c|}{ te } \\
\hline 3 & $\begin{array}{l}\text { F: CGCAAAGACATCTCCGCTC, } \\
\text { R: AGAGCAAATCGAAGTTGGCG }\end{array}$ & $(\mathrm{AG})_{10}$ & $94-110$ & NED & .1 \\
\hline \multicolumn{6}{|c|}{ 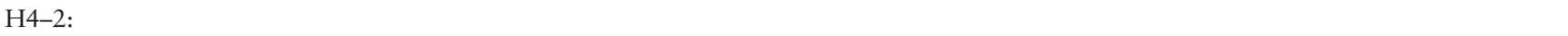 } \\
\hline 3 & $\begin{array}{l}\text { F: CGCAAAGACATCTCCGCTC, } \\
\text { R: AGAGCAAATCGAAGTTGGCG }\end{array}$ & $(\mathrm{AG})_{10}$ & $113-125$ & NED & .1 \\
\hline \multicolumn{6}{|c|}{ (2) } \\
\hline 3 & $\begin{array}{l}\text { F: CCTGGGTTTGTTGGCTTCC, } \\
\text { R: TTCCACCTTCGAATTGGCG }\end{array}$ & $(\mathrm{AG})_{9}(\mathrm{GT})_{7}$ & $184-204$ & YAM & .4 \\
\hline
\end{tabular}

a Size range based on all 106 individuals.

b Fluorescent dye for forward primers.

c Final concentration of each primer pair $(\mu \mathrm{M})$ in each multiplex PCR. For primer development procedure, see Zhang et al. (2013).

function in the generalized linear mixed effects environment of SPSS v. 22.0.0 (IBM, Armonk, NY). Outcrossing rates, which vary between 0 and 1 , were arcsine transformed to approximate assumptions of normality. As a fixed effect, we used the terminal herkogamy class (high: $>1 \mathrm{~mm}$ vs. low: $0-1 \mathrm{~mm}$ ). To account for hierarchical data structure, we included population $(\mathrm{CH} 1, \mathrm{CH} 2$, $\mathrm{CH} 3$, and $\mathrm{CH} 4$ ) as random effect. Due to unbalance in the data set, we used the Satterthwaite's method to determine the approximate denominator degree of freedom. Second, we tested whether high-herkogamous plants varied less in outcrossing rates than low-herkogamous plants. This would be expected if high herkogamy precludes autonomous selfing, while low terminal herkogamy allows for outcrossing early in anthesis followed by delayed autonomous selfing. To this end, we quantified the variation of outcrossing rates with the coefficient of variation $(\mathrm{CV}=\sigma / \mu$, where $\sigma$ and $\mu$ indicate the standard deviation and mean of $t_{\mathrm{mf}}$, respectively) for each population and terminal herkogamy class, and used a one-tailed paired $t$-test. All statistical analyses were performed using SPSS v. 22.0.0.
Inbreeding depression. To address question iii, we estimated the relative fitness of selfed offspring, $w$, using an approach analogous to Opedal et al. (2016), based on the populationlevel inbreeding coefficient, $F$, and the selfing rate based on progeny arrays, $s_{\mathrm{m}}=1-t_{\mathrm{m}}$ (Ritland 1990; Ågren and Schemske 1993; Herlihy and Eckert 2002). Inbreeding coefficients reflect the breeding history of populations over several generations, where sustained high levels of inbreeding increase values of $F$ (Fyfe and Bailey 1951; reviewed by Jarne and David 2008). Assuming that $F$ is constant among generations (Ritland 1990), the estimator leverages the idea that some specific proportion of offspring reaching adulthood is expected to be selfed. If the selfing rate based on progeny arrays exceeds this expectation, some selfed seedlings must succumb before reaching adulthood due to inbreeding depression. To calculate $F$, we used the genotypes of 106 individuals from the four sampled populations. $F$ was calculated based on heterozygosity deficiency ( $F_{\text {IS }}$; Fyfe and Bailey 1951; Charlesworth 2003) using the software Genepop v. 4.2 (Rousset 2008) that implements a method 
based on Weir and Cockerham (1984). We also used $F_{\text {IS }}$ to calculate the populationwide outcrossing rate (based on adult genotypes) using the formula $t\left(F_{\text {IS }}\right)=1-s\left(F_{\text {IS }}\right)=1-\left[2 F_{\text {IS }} /\left(1+F_{\text {IS }}\right)\right]$. Inbreeding depression, $\delta$, was calculated as $\delta=1-w$, using equation (3) of Ritland (1990) for $w$, with standard errors derived from selfing rate variance using equation (4) of Ritland (1990). While $\delta>1$ indicates that selfed offspring is fitter than outcrossed offspring, $\delta<1$ indicates that selfed offspring is less fit than outcrossed offspring.

\section{Pollen Limitation}

The occurrence of pollen limitation (question iv) was tested in population $\mathrm{CH} 2$. The theoretical upper limit to seed set is given by the number of ovules per flower. If no undeveloped ovules are present in a fruit, actual seed set equals the theoretically maximal seed set; thus, seed set is neither pollen- nor resource-limited (Aizen and Harder 2007). If, however, undeveloped ovules are present in fruits of flowers that received copious pollen, resource limitation must explain the discrepancy between actual seed set and theoretically maximal seed set. De Vos et al. (2012) established that seed set of open pollinated plants of $P$. halleri ranges from 0 to 1 seeds per ovule. To determine whether values less than 1 could be due to outcrossed pollen receipt limiting total seed set, 10 randomly selected plants in population $\mathrm{CH} 2$ (four of class $0-1 \mathrm{~mm}$ herkogamy and six of class $>1 \mathrm{~mm}$ herkogamy) received a pollen supplementation treatment. To this end, stigmas of all open flowers were brushed with dehisced pollen-containing anthers from at least three different plants, while unopened and wilted flowers were clipped (typically one flower per plant). Two weeks later, wilted flowers were bagged individually before the capsules opened, and ripe capsules were collected at the end of the season. Seed set was classified as full or not full in three randomly selected flowers per plant, where full seed set was defined as a seed-to-ovule ratio that exceeded 0.9 (Totland 1997; de Vos et al. 2012). Because $P$. halleri has a mean ovule number (and thus theoretically maximal seed set) of about 300, we classified seed set as full when the number of undeveloped ovules in the capsule did not exceed 30. This experiment allows us to determine whether copious pollen receipt by (nearly) all flowers simultaneously allows for full seed set; i.e., the theoretically maximal seed set is achieved in the face of possible resource limitation to seed development (Aizen and Harder 2007).

\section{Results}

\author{
Herkogamy Measurement and Seed Set
}

Population-level surveys revealed that the four populations differed in terminal herkogamy: between $19 \%$ and $72 \%$ of the individuals belonged to the high-herkogamous class (terminal herkogamy $>1 \mathrm{~mm}$ ) with the remainder assigned to the lowherkogamous class (table 2; fig. 2A). Herkogamy assignments were congruent between observations performed on two different days on different flowers within the same inflorescence at the end of anthesis, when herkogamy reaches its lowest level (i.e., terminal herkogamy; data not shown). The mean among populations $(50.7 \%)$ was approximated well by the plants used for genetic analyses: 58 plants belonged to the herkogamy class $0-1 \mathrm{~mm}(\sim 55 \%)$, and 47 plants belonged to herkogamy class $>1 \mathrm{~mm}(\sim 45 \%)$.

Among the plants used for genetic analyses, 48 plants produced only seedless fruits ( 26 with high and 22 with low terminal herkogamy) and 58 had at least one seed-carrying fruit (21 with high and 37 with low terminal herkogamy). Proportions of plants that produced seed-carrying fruits varied among the four populations and the two herkogamy classes (fig. $2 \mathrm{~B}$ ). Proportions ranged from $17 \%(\mathrm{CH} 3)$ to $77 \%(\mathrm{CH} 4)$ in the high-herkogamous plants and from $43 \%(\mathrm{CH} 3)$ to $76 \%$ (CH1) in the low-herkogamous plants. In all populations, more of the low-herkogamous than the high-herkogamous plants had seed-carrying fruits, with the exception of population $\mathrm{CH} 4$, where more of the high-herkogamous than the lowherkogamous plants had seed-carrying fruits (77\% vs. $50 \%)$.

\section{Genetic Variation}

The 106 genotyped adult individuals harbored a total of 54 alleles for the 11 microsatellite loci, with a range of two to eight alleles per locus (table A1). Genetic variation for each population is summarized in table 2 . The mean number of alleles per locus, $N_{\mathrm{a}}$, ranged from 3.46 in population $\mathrm{CH} 1$ to 3.73 in population $\mathrm{CH} 2$. Mean allelic richness, $A$, and Nei's gene diversity, $H_{\mathrm{S}}$, were lowest in population $\mathrm{CH} 1$ (3.42 and 0.417, respectively) and highest in population $\mathrm{CH} 4$ (3.60 and 0.525, respectively). The inbreeding coefficient, $F_{\text {IS }}$, ranged from 0.132 in population $\mathrm{CH} 1$ to 0.200 in population $\mathrm{CH} 2$.

Table 2

Population-Level Variation among Four Populations of Primula halleri

\begin{tabular}{lcccccccccc}
\hline Population & Latitude $\left({ }^{\circ} \mathrm{N}\right)$ & Longitude $\left({ }^{\circ} \mathrm{E}\right)$ & Elevation $(\mathrm{m})$ & $\begin{array}{c}\text { \% of high- } \\
\text { herkogamous plants }\end{array}$ & $\begin{array}{c}\text { Sample size } \\
\text { (genetic variation) }\end{array}$ & $N_{\mathrm{a}}$ & $H_{\mathrm{S}}$ & $F_{\text {IS }}$ & $t\left(F_{\text {IS }}\right)$ \\
\hline $\mathrm{CH} 1$ & 46.349 & 8.153 & 2360 & 18.6 & 24 & 3.46 & $3.42 .417 .132 \pm .054 .727$ \\
$\mathrm{CH} 2$ & 46.381 & 8.228 & 2230 & 60.3 & 32 & 3.73 & 3.54 & $.482 .200 \pm .041$ & .654 \\
$\mathrm{CH} 3$ & 46.386 & 8.249 & 2300 & 72.0 & 25 & 3.55 & 3.50 & $.485 .177 \pm .051$ & .608 \\
$\mathrm{CH} 4$ & 46.382 & 8.264 & 2100 & 52.0 & 25 & 3.64 & 3.60 & $.525 .168 \pm .068$ & .663 \\
Mean & & & & 50.7 & $106^{\mathrm{a}}$ & 3.59 & 3.51 .477 & .169 & .663 \\
\hline
\end{tabular}

Note. $\quad N_{\mathrm{a}}=$ mean number of alleles per locus; $A=$ mean allelic richness; $H_{\mathrm{S}}=$ mean Nei's gene diversity; $F_{\mathrm{IS}}=$ inbreeding coefficient; $t\left(F_{\text {IS }}\right)=$ outcrossing rates estimated from inbreeding coefficient $F_{\text {IS }}$.

a Total. 

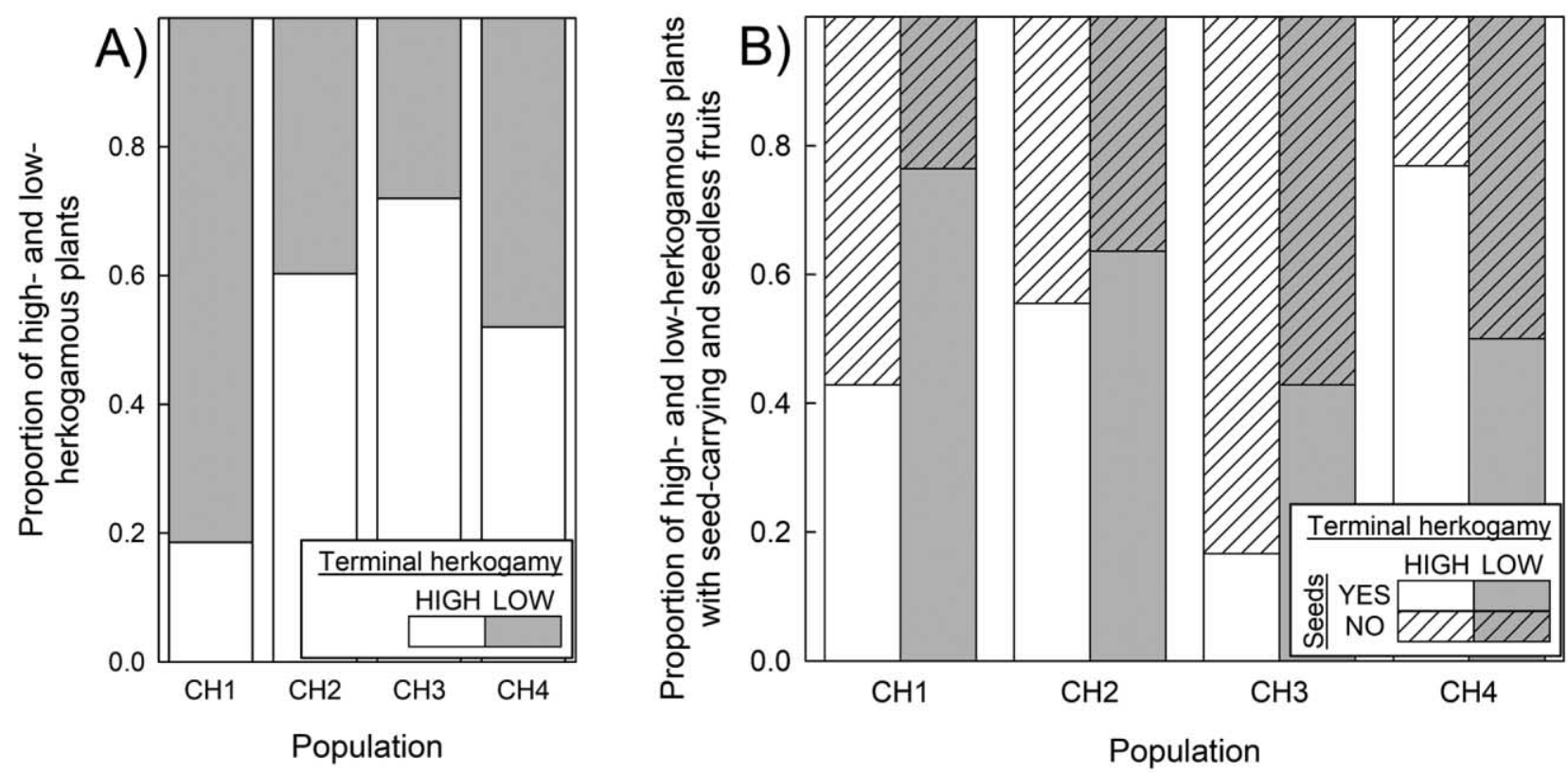

Fig. 2 A, Proportion of high-herkogamous $(>1 \mathrm{~mm})$ and low-herkogamous $(0-1 \mathrm{~mm})$ plants in four Swiss populations of Primula halleri (25-131 plants per population). B, Proportion of plants with seed-carrying and seedless fruits in the two herkogamy groups in the four populations (24-32 plants per population).

\section{Genetic Outcrossing Rates}

Outcrossing rates for all four populations fell within the mixed mating range, conventionally defined between 0.2 and 0.8 (table 2; Lande and Schemske 1985). Population-level outcrossing rates, $t\left(F_{\text {IS }}\right)$, based on the inbreeding coefficient, $F_{\text {IS }}$, ranged from 0.608 in population $\mathrm{CH} 3$ to 0.727 in population $\mathrm{CH} 1$. Multilocus outcrossing rates $\left(t_{\mathrm{m}}\right)$ estimated from progeny arrays ranged from 0.557 in population $\mathrm{CH} 1$ to 0.718 in population $\mathrm{CH} 4$, and the average single-locus outcrossing rates $\left(t_{\mathrm{s}}\right)$ ranged from 0.473 in population $\mathrm{CH} 1$ to 0.630 in population $\mathrm{CH} 4$ (table 3). Estimates of $\left(t_{\mathrm{m}}-t_{\mathrm{s}}\right)$ as a measure of biparental inbreeding were fairly low and ranged from 0.084 in population $\mathrm{CH} 1$ to 0.143 in population $\mathrm{CH} 2$ (table 3 ).

\section{Herkogamy and Family-Level Outcrossing Rates}

Multilocus estimates of outcrossing rates $\left(t_{\mathrm{m}}\right.$ and $\left.t_{\mathrm{mf}}\right)$ varied greatly among individual mother plants and populations (tables 3, A2; fig. 3). Family-level multilocus outcrossing rates $\left(t_{\mathrm{mf}}\right)$ ranged from 0.08 to 1 across all four populations, with values of 0.080 to 1 in plants with low terminal herkogamy and 0.428 to 1 in plants with high terminal herkogamy (table A2). Across populations, $t_{\mathrm{mf}}$ was on average higher in high-herkogamous plants than in low-herkogamous plants (0.829 and 0.695 , respectively), but not significantly so $\left(F_{1,48}=\right.$ $3.257, P=0.077$; fig. $3 B$ ). However, the CV estimated from $t_{\mathrm{mf}}$ was significantly higher in low-herkogamous than in highherkogamous plants, indicating greater variability of $t_{\mathrm{mf}}$ among

Table 3

Family-Level Outcrossing Rates among Four Populations of Primula halleri

\begin{tabular}{lcccrr}
\hline Population & Sample size (family/offspring) & $t_{\mathrm{m}}$ & $t_{\mathrm{s}}$ & $t_{\mathrm{m}}-t_{\mathrm{s}}$ & $\delta$ \\
\hline $\mathrm{CH} 1$ & $16 / 360$ & $.557 \pm .058$ & $.473 \pm .065$ & $.084 \pm .030$ & $.628 \pm .090$ \\
$\mathrm{CH} 2$ & $20 / 414$ & $.684 \pm .067$ & $.541 \pm .040$ & $.143 \pm .037$ & $-.082 \pm .335$ \\
$\mathrm{CH} 3$ & $6 / 82$ & $.657 \pm .169$ & $.544 \pm .134$ & $.113 \pm .074$ & $.176 \pm .618$ \\
$\mathrm{CH} 4$ & $16 / 314$ & $.718 \pm .058$ & $.630 \pm .063$ & $.088 \pm .049$ & $-.028 \pm .295$ \\
Mean & $58 / 1170^{\mathrm{a}}$ & .654 & .55 & .107 & .174 \\
\hline
\end{tabular}

Note. $\quad t_{\mathrm{m}}=$ multilocus outcrossing rates; $t_{\mathrm{s}}=$ single-locus outcrossing rates; $t_{\mathrm{m}}-t_{\mathrm{s}}=$ biparental inbreeding; $\delta=$ inbreeding depression estimated using Ritland's (1990) estimator assuming constant $F_{\mathrm{IS}}$ between generations. Estimates are given as means \pm standard errors of sampling means.

a Total. 

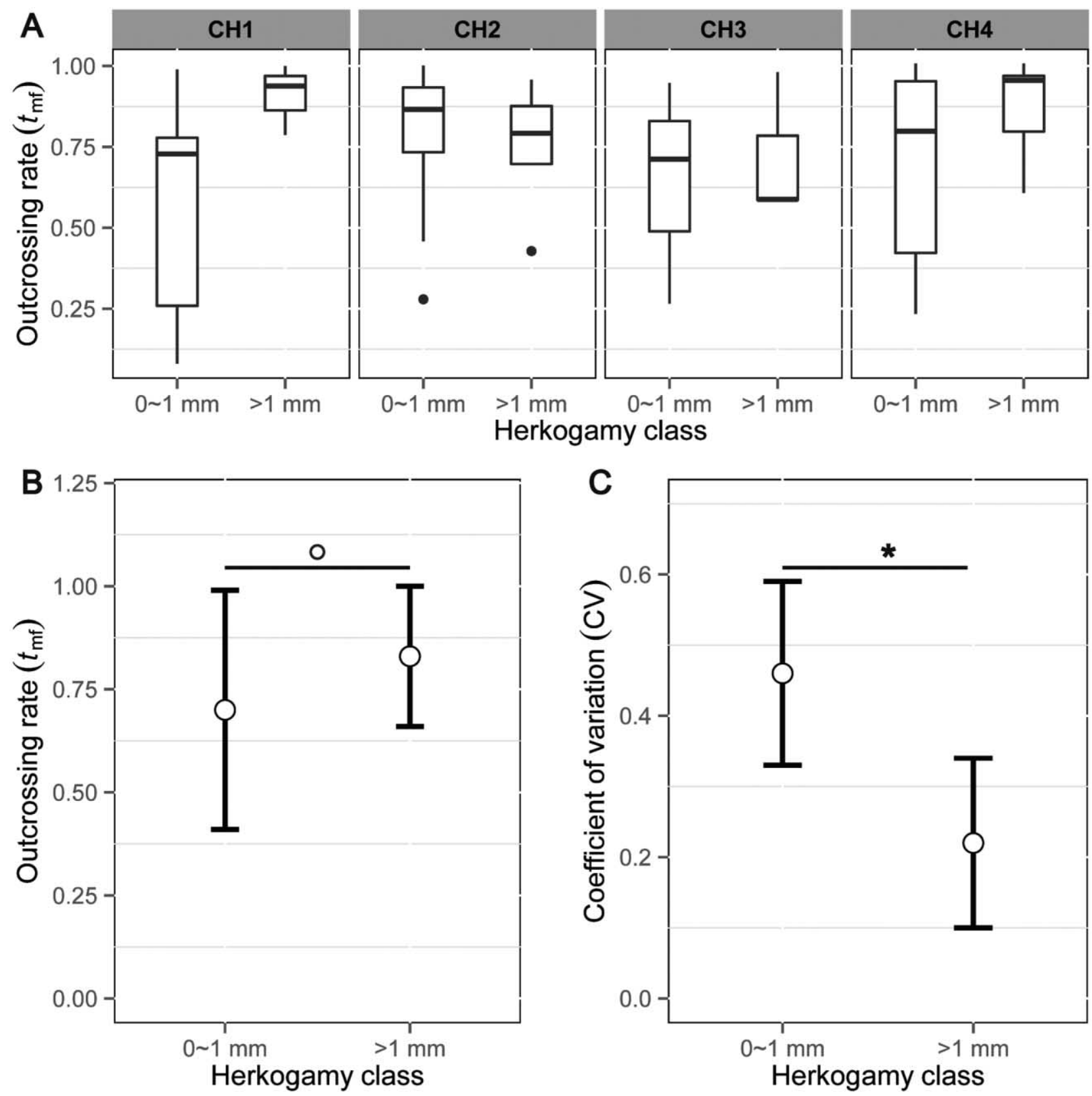

Fig. 3 A, Family-level outcrossing rates of four Swiss populations of Primula halleri (CH1, $\mathrm{CH} 2, \mathrm{CH} 3$, and $\mathrm{CH} 4$; total 58 plants) for herkogamy classes $0-1 \mathrm{~mm}$ and $>1 \mathrm{~mm}$ estimated using progeny arrays. Mean values and standard deviations of family-level outcrossing rates for each maternal plant $\left(t_{\mathrm{mf}} ; B\right)$ and coefficients of variation estimated from $t_{\mathrm{mf}}$ in the two herkogamy classes $(C)$. Significance levels: $P \leq 0.05$ (asterisk) and $P=0.077$ (open circle).

low-herkogamous than among high-herkogamous plants $\left(t_{3}=\right.$ 2.600, $P=0.040$; fig. $3 C$ ).

\section{Inbreeding Depression}

Estimates of inbreeding depression, $\delta$, varied among populations (table 3; underlying values of $F$ and $s$ are given in tables 2 and 3 , respectively). In population $\mathrm{CH} 1$, it was estimated to be considerable with $\delta=0.628 \pm 0.090$, while in populations $\mathrm{CH} 2, \mathrm{CH} 3$, and $\mathrm{CH} 4, \delta$ ranged from $-0.082 \pm 0.335$ to
$0.176 \pm 0.618$, with the large standard errors suggesting that the estimator behaved poorly when $\delta$ was small. Overall, these estimates tentatively indicate presence of inbreeding depression, but population-level variation cannot be interpreted conclusively.

\section{Pollen Supplementation Experiment}

Pollen supplementation experiments indicated that seed set of open pollinated plants with less than one seed per ovule is 
due to pollen limitation rather than resource limitation. All examined fruits that received copious pollen met the threshold for full seed set (i.e., $<30$ undeveloped ovules per flower; observed range $0-28$, mean 9.5 , SD 8.4).

\section{Discussion}

Herkogamy is widely interpreted as a key floral trait that reduces interactions between male and female floral functions (Barrett 2002) and, importantly, prevents autogamy in selfcompatible plants (Webb and Lloyd 1986). Its occurrence in self-compatible, monomorphic (i.e., homostylous) primrose species that evolved from obligately outcrossing, heterostylous ancestors (Mast et al. 2006; de Vos et al. 2014a, 2014b) is therefore enigmatic. The loss of traits that enforce outcrossing is thought to be favored in environmental conditions where outcrossing opportunities are limited due to mate limitation and/or pollinator limitation, so that autonomous selfing may provide reproductive assurance (Eckert et al. 2006; Busch and Delph 2012).

Yet, if herkogamy reduces the probability for autonomous selfing, how does the reproductive system of homostylous, herkogamous species function? This study contributes to elucidating this question by providing insights into the effects of variation in herkogamy at different hierarchical levels (from populations to individuals) on the mating system of the only monomorphic primrose of the European Alps, Primula halleri, a species that has long drawn the attention of researchers interested in the evolution of heterostylous species groups (e.g., Scott 1865; Ernst 1925, 1951; de Vos et al. 2012). We demonstrate that, rather than being a predominant selfer, all populations of $P$. halleri have a mixed mating system (Lande and Schemske 1985), with outcrossing rates $\left(t_{m}\right)$ ranging from 0.557 to 0.718 $\left(t\left(F_{\text {IS }}\right)\right.$ ranges from 0.608 to 0.7270$)$, and inbreeding coefficients $\left(F_{\text {IS }}\right)$ ranging from 0.132 to 0.200 (table 2 ), but there are important differences between individuals that relate to variation in herkogamy. Moreover, we document that copious stigmatic pollen loads lead to full seed set, indicating that lower seed set is due to pollen- rather than resource-limitation. We also tentatively estimate that inbreeding depression exceeds zero, with possible differences among populations (table 3), corroborating early experimental data by Ernst (1951). Here, we interpret these results in the light of evolutionary dynamics of self-compatible species compared with their outcrossing ancestors and the simultaneous effects of herkogamy variation on outcrossing rates and seed set, while assessing the reliability of our estimates.

\section{Effects of Herkogamy on Mating}

Herkogamy diminished during anthesis in all individuals of $P$. halleri, but its terminal amount differed between individuals (fig. 1; de Vos et al. 2012). However, mean outcrossing rates did not significantly differ between high-herkogamous and lowherkogamous plants (fig. 3B). Indeed, even low-herkogamous plants, with anthers and stigmas separated by less than $1 \mathrm{~mm}$ at the end of anthesis, were characterized by relatively high mean outcrossing rates $\left(t_{\mathrm{mf}}=0.695\right.$; fig. $\left.3 A, 3 B\right)$. In fact, this estimate was only marginally significantly lower than that among high-herkogamous individuals (fig. $3 B$; mean $t_{\mathrm{mf}}=0.829$ ). The lack of a significant difference in the mean outcrossing rates of the two herkogamy classes is surprising for two reasons. First, most other studies that considered herkogamy variation among individuals found significantly diminished outcrossing in low-herkogamous individuals (e.g., Karron et al. 1997; Brunet and Eckert 1998; Takebayashi et al. 2006; Herlihy and Eckert 2007). Second, the absolute amount of herkogamy difference between classes was shown to greatly affect seed set under pollinator exclusion (de Vos et al. 2012), demonstrating that the autonomous component of selfing is affected by herkogamy. In contrast, the lack of an effect of herkogamy on the mean outcrossing rate is in line with the observation that in P. halleri, as in some other species (e.g., Luijten et al. 1999; Duan et al. 2010), initial herkogamy early in anthesis provides ample opportunities for outcrossing, regardless of its terminal level in late flowers. Consistently with the relatively high mean levels of outcrossing detected in both herkogamy classes, the inbreeding coefficients $\left(F_{\text {IS }}\right.$, and its derivative, $\left.t\left(F_{\text {IS }}\right)\right)$ indicate not extreme but, rather, moderate inbreeding across the preceding generations (table 2).

Despite lack of significant differences in means, we do find that high-herkogamous individuals have consistently high outcrossing rates, while low-herkogamous individuals display a large range of estimates (fig. 3; table A2). This difference is reflected in the significantly different CVs of 0.21 and 0.42 , respectively $(P<0.05$; fig. 3$)$. This result is broadly in line with Pérez et al. (2013), who demonstrated increased variability in outcrossing rates in a delayed-selfing Schizanthus species compared with a pollinator-dependent species, but that study documented variability among - rather than within-populations. For $P$. halleri, the consistently high outcrossing rates of high-herkogamous plants (and thus low CV values) can be attributed to the absence of an opportunity to autonomously self. De Vos et al. (2012) demonstrated that high-herkogamous and low-herkogamous plants have a similar but low probability to receive outcross pollen, as they found no significant effect of herkogamy on seed set in plants of which all flowers had been emasculated. Rather, they found frequently low seed set among all emasculated plants. Thus, both low-herkogamous and highherkogamous plants can outcross, should a rare pollinator visit occur; high-herkogamous plants are fully pollinator dependent, while low-herkogamous plants can self in addition to outcross. Further support for this interpretation comes from the result that seed set is generally higher in open-pollinated, low-herkogamous compared with high-herkogamous plants (fig 2B; de Vos et al. 2012). To our knowledge, an effect of a floral trait on the variability (rather than the mean) of outcrossing rates across individuals within populations has not yet been reported.

To summarize, our genetic estimates of the mating system suggest that decreasing herkogamy during anthesis represents a delayed selfing mechanism that functions mainly in plants with low terminal herkogamy. Conversely, plants with high terminal herkogamy, while still displaying lower herkogamy in older flowers (de Vos et al. 2012), do not decrease herkogamy sufficiently to allow for autonomous selfing late in anthesis but maintain outcrossing opportunity throughout the entire period of anthesis instead. Although it is possible that a shift toward autonomous selfing compromises the duration of the period for outcrossing in low-herkogamous plants, it appears that outcrossing opportunities are sufficiently ample in both categories of herkogamy to maintain considerably high mean outcrossing rates. 


\section{Simultaneous Effects on Number of Seeds and Mating Mode of Seed Production}

Individuals that did not set seed were necessarily excluded from genetic analyses; thus, interpretation of the mating system based on outcrossing rates alone may miss important aspects (Harder et al. 2008). Therefore, we now consider effects of herkogamy on the mating origin of seeds (this study) jointly with those on seed number (fig. 2B; de Vos et al. 2012) and pollinator exclusion and emasculation experiments (de Vos et al. 2012; summarized above). These results jointly suggest that variation in herkogamy may impose a seed quality versus seed quantity trade-off. Seedless fruits were more common among highherkogamous plants compared with low-herkogamous plants (fig. 2B), in line with de Vos et al.'s (2012) finding that $1 \mathrm{~mm}$ terminal herkogamy represents an approximate threshold above which seed set under pollinator exclusion is impeded. Thus, substantial terminal herkogamy may prevent autonomous selfing and ensure consistently high outcrossing rates (fig. 3, discussed above), but it simultaneously implies risking a low reproductive output (fig. 2B; de Vos et al. 2012). In contrast, in plants with low terminal herkogamy, seed set through outcrossing is similar to that in high-herkogamous plants (fig. 3; emasculation treatment; de Vos et al. 2012). However, total seed set is higher in low-herkogamous compared to high-herkogamous plants, likely due to differences in contribution of seeds produced via autonomous (and perhaps facilitated) selfing. Thus, while the reproductive patterns of the low-herkogamous individuals are in line with the reproductive assurance hypothesis (higher seed set of mixed mating origin; Arroyo et al. 2006; Busch and Delph 2006; Eckert et al. 2006), the existence of high-herkogamous plants is enigmatic (lower seed set, more consistently outcrossed). Why has selection not eradicated high-herkogamous plants?

It is possible that variation in herkogamy simply represents a nonheritable by-product of the particularities of floral development, resulting in an adaptively inaccurate morphology (Armbruster et al. 2009). However, several studies found herkogamy to have a strong genetic basis (e.g., Herlihy and Eckert 2007; Luo and Widmer 2013), and a comprehensive review concluded that the trait is typically highly heritable and evolvable (Opedal et al. 2017). Moreover, the profound functional implications of sexual organ position (de Vos et al. 2012; Keller et al. 2012, 2014, 2016) justify speculating about possible adaptive explanations for the existence of high-herkogamous plants.

It seems unlikely that inbreeding depression provides a sufficient explanation for the existence of high-herkogamous plants. Delayed selfing, detected in low-herkogamous plants of $P$. halleri, should always be selected, because delayed selfing would allow for production of selfed seeds in addition to outcrossed seeds, not at the cost of outcrossed seeds (Lloyd and Schoen 1992), for it avoids pollen- and ovule-discounting costs of autonomous selfing (which would occur when gametes are used for selfing that could have been outcrossed; Herlihy and Eckert 2002). Thus, even when fitness increments from additional selfed seeds are small due to high inbreeding depression, as long as they are positive, they increase total fitness. We found evidence of low to moderate inbreeding depression $(\delta>0$; table 3$)$, in line with Ernst's (1951) experimental work documenting, at most, moderately lower seed germination ratios of selfed seeds (on average
$20 \%-30 \%$ lower after manual self-pollination compared with cross-pollination). Jointly these results suggest that some reproductive fitness is gained from selfing. Therefore, inbreeding depression does not provide a sufficient explanation for the frequent occurrence of high-herkogamous plants.

As an alternative explanation, low-herkogamous plants may even incur negative fitness effects from setting additional selfed seeds, if the resource cost of their production compromises future investment in reproduction in following flowering seasons (Obeso 2002; Jiménez 2014). Such costs of reproduction are believed to be common and have been demonstrated experimentally in a wide range of iteroparous species (e.g., through clipping flowers followed by demonstrating increased reproductive effort in a subsequent flowering season; Obeso 2002). Thus, it is possible that the production of additional selfed seeds in low-herkogamous plants incurs important resource costs. Such resource costs can constitute resource discounting when that expenditure compromises future opportunities for outcrossing (e.g., Herlihy and Eckert 2002). This could be investigated by tracking reproductive output year to year in highherkogamous and low-herkogamous plants with and without an emasculation treatment, but direct evidence for $P$. halleri is lacking. Nevertheless, in the closely related distylous $P$. farinosa, prevention of seed production indeed promotes flower production in the next year, especially in plants with large inflorescences (Euler et al. 2012). Thus, selection may not eliminate highherkogamous plants in favor of low-herkogamous plants despite lower seed set in the former compared with the latter, if negative fitness effects due to resource discounting in low-herkogamous plants exceed the fitness increments due to additional selfed seeds.

To summarize, herkogamy variation simultaneously affects reproductive output (fig. $2 B$; de Vos et al. 2012) and mating origin of seeds (figs. 1, 3). The fact that low-herkogamous individuals appear to display a best-of-both-worlds solution to their unreliable pollination environment makes the existence of highherkogamous individuals enigmatic, unless the production of selfed seeds following delayed selfing in low-herkogamous individuals generates resource costs that negatively affect future performance (which we term resource discounting). If seed quantity and quality are negatively related in self-compatible species, it is likely that variation in herkogamy affects whether plants produce few high-quality seeds versus many lower-quality seeds. More generally, our results point to the importance of considering the joint effects of traits on outcrossing rates, seed set, and resource costs of reproduction to find explanations for the striking diversity of plant mating systems.

\section{Conclusion}

While homostyly has been interpreted as an adaptation to promote autonomous selfing in marginal environments with low pollinator availability, such as the alpine meadows where $P$. halleri occurs, the species' mixed mating system adds nuance to this predominant view. Evolution in pollinator-limited environments does not appear to necessarily drive selection for autogamy and reproductive assurance, as would be expected under the reduced reliance on pollinators hypothesis (Arroyo et al. 2006): although $P$. halleri displays a delayed selfing mechanism 
via herkogamy variation during anthesis, it only functions in a subset of the individual plants. Rather, our results seem to corroborate García-Camacho and Totland's (2009) demonstration that there is no evidence for assuming that self-compatibility in the alpine generally relieves pollen limitation. At the same time, $P$. halleri does not entirely reflect a clear evolutionary trajectory in line with the increased pollination probability hypothesis through increased floral display either. Although, compared with its closely related heterostylous lowland species, it has larger floral size (Ernst 1962; Richards 2003; de Vos et al. 2014b) and considerably fewer flowers (J. M. de Vos, personal observation), suggesting that the evolution of a floral size/flower number tradeoff relation is also important. Instead, our study underlines the emergent view that to explain morphological and reproductive functional diversity of flowers and inflorescences, it is necessary to understand the interactions between pollination ecological, resource-economic, and genetic phenomena.

\section{Acknowledgments}

We thank the China Scholarship Council, the University of Zurich, and the Georges and Antoine Claraz-Schenkung for financial support; the canton of Valais for granting permission for fieldwork; and the editor and two anonymous reviewers for their constructive comments. J. M. de Vos was supported in part by the Swiss National Science Foundation (PBZHP3_147199). We dedicate this project to the memory of Professor Sylvia (Tass) Kelso of Colorado College, whose insightful observations first suggested the potential importance of herkogamy in homostylous primroses.

\section{Literature Cited}

Ågren J, DW Schemske 1993 Outcrossing rate and inbreeding depression in two annual monoecious herbs, Begonia hirsuta and B. semiovata. Evolution 47:125-135.

Aizen MA, LD Harder 2007 Expanding the limits of the pollen-limitation concept: effects of pollen quantity and quality. Ecology 88:271-281.

Armbruster WS, TF Hansen, C Pélabon, R Pérez-Barrales, J Maad 2009 The adaptive accuracy of flowers: measurement and microevolutionary patterns. Ann Bot 103:1529-1545.

Armbruster WS, CP Mulder, BG Baldwin, S Kalisz, B Wessa, H Nute 2002 Comparative analysis of late floral development and matingsystem evolution in tribe Collinsieae (Scrophulariaceae s.1.). Am J Bot 89:37-49.

Arroyo MTK, J Armesto, RB Primack 1985 Community studies in pollination ecology in the high temperate Andes of central Chile. II. Effect of temperature on visitation rates and pollination possibilities. Plant Syst Evol 149:187-203.

Arroyo MTK, MS Munoz, C Henriquez, I Till-Bottraud, F Perez 2006 Erratic pollination, high selfing levels and their correlates and consequences in an altitudinally widespread above-tree-line species in the high Andes of Chile. Acta Oecol 30:248-257.

Arroyo MTK, RB Primack R, J Armesto 1982 Community studies in pollination ecology in the high temperate Andes of central Chile. I. Pollination mechanisms and altitudinal variation. Am J Bot 69:82-97.

Ashman TL, TM Knight, JA Steets, P Amarasekare, M Burd, DR Campbell, MR Dudash, et al 2004 Pollen limitation of plant reproduction: ecological and evolutionary causes and consequences. Ecology 85:2408-2421.

Barrett SCH 1992 Evolution and function of heterostyly. Springer, Berlin.

2002 Sexual interference of the floral kind. Heredity 88:154159.

2003 Mating strategies in flowering plants: the outcrossingselfing paradigm and beyond. Philos Trans R Soc B 358:991-1004.

Barrett SCH, LD Harder 1996 Ecology and evolution of plant mating. Trends Ecol Evol 11:73-79.

Barrett SCH, JS Shore 1987 Variation and evolution of breeding systems in the Turnera ulmifolia L. complex (Turneraceae). Evolution 41:340-354.

Bingham RA, AR Orthner 1998 Efficient pollination of alpine plants. Nature 391:238-239.

Brunet J, CG Eckert 1998 Effects of floral morphology and display on outcrossing in Blue Columbine, Aquilegia caerulea (Ranunculaceae). Funct Ecol 12:596-606.
Busch JW, LF Delph 2012 The relative importance of reproductive assurance and automatic selection as hypotheses for the evolution of self-fertilization. Ann Bot 109:553-562.

Carlson ML, MT Gisler, S Kelso 2008 The role of reproductive assurance in the Arctic: a comparative study of a homostylous and distylous species pair. Arct Antarct Alp Res 40:39-47.

Charlesworth D 2003 Effects of inbreeding on the genetic diversity of populations. Proc R Soc B 358:1051-1070.

Charlesworth D, JH Willis 2009 The genetics of inbreeding depression. Nat Rev Genet 10:783-796.

Cohen JI 2010 "A case to which no parallel exists": the influence of Darwin's different forms of flowers. Am J Bot 97:701-716.

Cullings KW 1992 Design and testing of a plant-specific PCR primer for ecological and evolutionary studies. Mol Ecol 1:233-240.

Darwin C 1877 The different forms of flowers on plants of the same species. J Murray, London.

de Nettancourt D 2001 Incompatibility and incongruity in wild and cultivated plants. Springer, Berlin.

Devaux C, R Lande, E Porcher 2014 Pollination ecology and inbreeding depression control individual flowering phenologies and mixed mating. Evolution 68:3051-3065.

de Vos JM, CE Hughes, GM Schneeweiss, BR Moore, E Conti 2014a Heterostyly accelerates diversification via reduced extinction in primroses. Proc R Soc B 281:20140075.

de Vos JM, B Keller, ST Isham, S Kelso, E Conti 2012 Reproductive implications of herkogamy in homostylous primroses: variation during anthesis and reproductive assurance in alpine environments. Funct Ecol 26:854-865.

de Vos JM, RO Wueest, E Conti $2014 b$ Small and ugly? phylogenetic analyses of the "selfing syndrome" reveal complex evolutionary fates of monomorphic primrose flowers. Evolution 68:10421057.

Doyle JJ, JL Doyle 1987 A rapid DNA isolation procedure for small quantities of fresh leaf tissue. Phytochem Bull 19:11-15.

Duan YW, A Dafni, QZ Hou, YP He, JQ Liu 2010 Delayed selfing in an alpine biennial Gentianopsis paludosa (Gentianaceae) in the Qinghai-Tibetan plateau. J Integr Plant Biol 52:593-599.

Eckert CG, KE Samis, S Dart 2006 Reproductive assurance and the evolution of uniparental reproduction in flowering plants. Pages 183-203 in LD Harder, SCH Barrett, eds. Ecology and evolution of flowers. Oxford University Press, Oxford.

El Mousadik A, RJ Petit 1996 High level of genetic differentiation for allelic richness among populations of the argan tree [Argania 
spinosa (L.) Skeels] endemic to Morocco. Theor Appl Genet 92: 832-839.

Ernst A 1925 Zur blütenbiologie und genetik von Primula longiflora All. Veröff Geobot Inst Rübel Zürich 3:628-654.

1951 "Maternal hybrids" nach inter-spezifischen Bestaubung in der Gattung Primula. 2. Sektion Farinosae. Arch Julius Klaus Stift Vererbungsforsch Sozialanthropol Rassenhyg 26:187-322. 448

1962 Stammesgeschichtliche Untersuchungen zum HeterostylieProblem. 7. Stand des Nachweises monomorpher Arten, homostyler Sippen und anderer genetisch bedingter Abweichungen vom "klassischen" Blütendimorphismus in den Sektionen der Gattung Primula. Arch Julius Klaus Stift Vererbungsforsch Sozialanthropol Rassenhyg 37:1-127.

Euler TV, J Ågren, J Ehrlén 2012 Floral display and habitat quality affect cost of reproduction in Primula farinosa. Oikos 121:14001407.

Fyfe JL, NTJ Bailey 1951 Plant breeding studies in leguminous forage crops. I. Natural cross-breeding in winter beans. J Agric Sci 41:371-378.

García-Camacho R, Ø Totland 2009 Pollen limitation in the alpine: a meta-analysis. Arct Antarct Alp Res 41:103-111.

Goldberg EE, JR Kohn, R Lande, KA Robertson, SA Smith, B Igić 2010 Species selection maintains self-incompatibility. Science 330: 493-495.

Goodwillie C, S Kalisz, CG Eckert 2005 The evolutionary enigma of mixed mating systems in plants: occurrence, theoretical explanations, and empirical evidence. Annu Rev Ecol Evol Syst 36:47-79.

Goudet J 1995 FSTAT (version 1.2): a computer program to calculate F-statistics. J Hered 86:485-486.

Guggisberg A, G Mansion, E Conti 2009 Disentangling reticulate evolution in an arctic-alpine polyploid complex. Syst Biol 58:55-73.

Guggisberg A, G Mansion, S Kelso, E Conti 2006 Evolution of biogeographic patterns, ploidy levels, and breeding systems in a diploid-polyploid species complex of Primula. New Phytol 171: 617-632.

Haddadchi A, M Fatemi 2015 Self-compatibility and floral traits adapted for self-pollination allow homostylous Nymphoides geminata (Menyanthaceae) to persist in marginal habitats. Plant Syst Evol 301:239-250.

Hamrick JL, MJW Godt 1996 Effect of life history traits on genetic diversity in plant species. Philos Trans R Soc B 351:1291-1298.

Harder LD, MA Aizen 2010 Floral adaptation and diversification under pollen limitation. Philos Trans R Soc B 365:529-543.

Harder LD, SA Richards, MB Routley 2008 Effects of reproductive compensation, gamete discounting and reproductive assurance on mating-system diversity in hermaphrodites. Evolution 62:157-172.

Harder LD, MB Routley 2006 Pollen and ovule fates and reproductive performance by flowering plants. Pages 61-80 203 in LD Harder, SCH Barrett, eds. Ecology and evolution of flowers. Oxford University Press, Oxford.

Herlihy CR, CG Eckert 2002 Genetic cost of reproductive assurance in a self-fertilizing plant. Nature 416:320-323.

2007 Evolutionary analysis of a key floral trait in Aquilegia canadensis (Ranunculaceae): genetic variation in herkogamy and its effect on the mating system. Evolution 61:1661-1674.

Holtsford TP, NC Ellstrand 1992 Genetic and environmental variation in floral traits affecting outcrossing rate in Clarkia tembloriensis (Onagraceae). Evolution 46:216-225.

Huu CN, C Kappel, B Keller, A Sicard, Y Takebayashi, H Breuninger, MD Nowak, et al 2016 Presence versus absence of CYP734A50 underlies the style-length dimorphism in primroses. eLife 5:e17956.

Igić B, JW Busch 2013 Is self-fertilization an evolutionary dead end? New Phytol 198:386-397.
Igić B, R Lande, JR Kohn 2008 Loss of self-incompatibility and its evolutionary consequences. Int J Plant Sci 169:93-104.

Jarne P, P David 2008 Quantifying inbreeding in natural populations of hermaphroditic organisms. Heredity 100:431-439.

Jiménez A, H Mansour, B Keller, E Conti 2014 Low genetic diversity and high levels of inbreeding in the Sinai primrose (Primula boveana), a species on the brink of extinction. Plant Syst Evol 300: 1199-1208.

Johnston MO, E Porcher, PO Cheptou, CG Eckert, E Elle, MA Geber, S Kalisz, et al 2009 Correlations among fertility components can maintain mixed mating in plants. Am Nat 173:1-11.

Johnston MO, DJ Schoen 1996 Correlated evolution of self-fertilization and inbreeding depression: an experimental study of nine populations of Amsinckia (Boraginaceae). Evolution 50:1478-1491.

Kalisz S, DW Vogler 2003 Benefits of autonomous selfing under unpredictable pollinator environments. Ecology 84:2928-2942.

Kalisz S, D Vogler, B Fails, M Finer, E Shepard, T Herman, R Gonzales 1999 The mechanism of delayed selfing in Collinsia verna (Scrophulariaceae). Am J Bot 86:1239-1247.

Kalisz S, DW Vogler, KM Hanley 2004 Context-dependent autonomous self-fertilization yields reproductive assurance and mixed mating. Nature 430:884-887.

Karron JD, RT Jackson, NN Thumser, SL Schlicht 1997 Outcrossing rates of individual Mimulus ringens genets are correlated with anther-stigma separation. Heredity 79:365-370.

Keller B, JM de Vos, E Conti 2012 Decrease of sexual organ reciprocity between heterostylous primrose species, with possible functional and evolutionary implications. Ann Bot 110:1233-1244.

Keller B, JM de Vos, A Schmidt-Lebuhn, JD Thomson, E Conti 2016 Both morph- and species-dependent asymmetries affect reproductive barriers between heterostylous primroses. Ecol Evol 6:6223-6244.

Keller B, JD Thomson, E Conti 2014 Heterostyly promotes disassortative pollination and reduces sexual interference in Darwin's primroses. Funct Ecol 28:1413-1425.

Knight TM, JA Steets, JC Vamosi, SJ Mazer, M Burd, DR Campbell, MR Dudash, et al 2005 Pollen limitation of plant reproduction: pattern and process. Annu Rev Ecol Evol Syst 36:467-497.

Körner C 2003 Alpine plant life: functional plant ecology of high mountain ecosystems. Springer Science and Business Media, New York.

Lande R, DW Schemske 1985 The evolution of self-fertilization and inbreeding depression in plants. 1. Genetic models. Evolution 39: 24-40.

Larson BM, SC Barrett 2000 A comparative analysis of pollen limitation in flowering plants. Biol J Linn Soc 69:503-520.

Li J, JM Cocker, J Wright, MA Webster, M McMullan, S Dyer, D Swarbreck, et al 2016 Genetic architecture and evolution of the S locus supergene in Primula vulgaris. Nat Plants 2:16188.

Lloyd DG 1992 Self-fertilization and cross-fertilization in plants. II. The selection of self-fertilization. Int J Plant Sci 153:370-380.

Lloyd DG, DJ Schoen 1992 Self-fertilization and cross-fertilization in plants. I. Functional dimensions. Int J Plant Sci 153:358-369.

Luijten SH, JG Oostermeijer, AC Ellis-Adam, JH den Nijs 1999 Variable herkogamy and autofertility in marginal populations of Gentianella germanica in the Netherlands. Folia Geobot 34:483-496.

Luo Y, A Widmer 2013 Herkogamy and its effects on mating patterns in Arabidopsis thaliana. PLoS One 8:e57902.

Mast AR, S Kelso, E Conti 2006 Are any primroses (Primula) primitively monomorphic? New Phytol 171:605-616.

Medrano M, CM Herrera, SCH Barrett 2005 Herkogamy and mating patterns in the self-compatible daffodil Narcissus longispathus. Ann Bot 95:1105-1111.

Medrano M, R Requerey, JD Karron, CM Herrera 2012 Herkogamy and mate diversity in the wild daffodil Narcissus longispathus: beyond the selfing-outcrossing paradigm in the evolution of mixed mating. Plant Biol 14:801-810. 
Moeller DA 2006 Geographic structure of pollinator communities, reproductive assurance, and the evolution of self-pollination. Ecology 87:1510-1522.

Morgan MT, WG Wilson 2005 Self-fertilization and the escape from pollen limitation in variable pollination environments. Evolution 59:1143-1148.

Müller H 1881 Alpenblumen, ihre Befruchtung durch Insekten und ihre Anpassungen an dieselben. Engelmann, Leipzig.

Nei M 1987 Molecular evolutionary genetics. Columbia University Press, New York, NY.

Obeso JR 2002 The costs of reproduction in plants. New Phytol 155: 321-348.

Opedal $\varnothing \mathrm{H}, \mathrm{E}$ Albertsen, WS Armbruster, R Pérez-Barrales, M Falahati-Anbaran, C Pélabon 2016 Evolutionary consequences of ecological factors: pollinator reliability predicts mating-system traits of a perennial plant. Ecol Lett 19:1486-1495.

Opedal ØH, GH Bolstad, TF Hansen, WS Armbruster, C Pélabon 2017 The evolvability of herkogamy: quantifying the evolutionary potential of a composite trait. Evolution 71:1572-1586.

Pérez F, C León, T Muñoz 2013 How variable is delayed selfing in a fluctuating pollinator environment? a comparison between a delayed selfing and a pollinator-dependent Schizanthus species of the high Andes. Evol Ecol 27:911-922.

Richards AJ 2003 Primula, 2nd ed. Timber, Batsford, London.

Rick CM, JF Fobes, M Holle 1977 Genetic variation in Lycopersicon pimpinellifolium: evidence of evolutionary change in mating systems. Plant Syst Evol 127:139-170.

Ritland K 1990 Inferences about inbreeding depression based on changes of the inbreeding coefficient. Evolution 44:1230-1241.

2002 Extensions of models for the estimation of mating systems using $\mathrm{n}$ independent loci. Heredity 88:221-228.

Ritland K, S Jain 1981 A model for the estimation of outcrossing rate and gene-frequencies using $\mathrm{n}$ independent loci. Heredity 47:35-52.
Rousset F 2008 Genepop '007: a complete re-implementation of the Genepop software for Windows and Linux. Mol Ecol Resour 8: 103-106.

Schulz A 1890 Beiträge zur Kenntnis der Bestäubungseinrichtungen und Geschlechtsverteilung bei den Pflanzen, II. Bibliotheca botanica, no. 17. T Fischer, Kassel.

Scott J 1865 Observations on the structure and function of the reproductive organs of the Primulaceae. Bot J Linn Soc 8:78-126.

Shaw DV, AL Kahler, RW Allard 1981 A multilocus estimator of mating system parameters in plant populations. Proc Natl Acad Sci USA 78:1298-1302.

Sosenski P, SE Ramos, CA Domínguez, K Boege, J Fornoni 2016 Pollination biology of the hexaploid self-compatible species Turnera velutina (Passifloraceae). Plant Biol 19:101-107.

Stebbins GL 1974 Flowering plants: evolution above the species level. Belknap, Cambridge.

Takebayashi N, DE Wolf, LF Delph 2006 Effect of variation in herkogamy on outcrossing within a population of Gilia achilleifolia. Heredity 96:159-165.

Totland Ø 1997 Limitations on reproduction in alpine Ranunculus acris. Can J Bot 75:137-144.

Webb CJ, DG Lloyd 1986 The avoidance of interference between the presentation of pollen and stigmas in angiosperms. II. Herkogamy. N Z J Bot 24:163-178.

Weber JJ, SG Weller, AK Sakai, A Nguyen, ND Tai, CA Domínguez, FE Molina-Freaner 2012 Purging of inbreeding depression within a population of Oxalis alpina (Oxalidaceae). Am J Bot 99:923932.

Weir BS, CC Cockerham 1984 Estimating F-statistics for the analysis of population structure. Evolution 38:1358-1370.

Zhang LR, E Conti, B Keller, MD Nowak 2013 Development of 12 polymorphic microsatellite loci in the high alpine perennial Primula halleri (Primulaceae). Appl Plant Sci 1:1300052. 